\title{
Words that Wound: Rethinking Online Hate Speech in South Africa
}

\section{Bright Nkrumah}

\section{Abstract}

Online violence and hate speech in cyberspace have become a major concern among previously disadvantaged groups and human rights activists in South Africa (Cuyler 2011; Ndou 2015). The remarkable expansion of the Internet as a platform for communication has been outdone by hate-based activity in cyberspace and extremist websites. The mobility and anonymity that the Internet provides has made expressions of hate and harassment easy on an abstract platform, which is often outside the remit of conventional security agencies (Lange 2007). By using technological, legal and political frameworks, this paper examines the conundrums involved in regulating hate speech on the Internet. It assesses the complexities inherent in South Africa's bilateral and/or multilateral partnerships, and challenges of unilateral domestic content legislation to regulate cyberspace. Whereas the state seeks to find common ground upon which to harmonise its approach to regulation, the paper examines how technological innovations can limit the harm triggered by hate speech. The paper recommends that there is the need for a broader mobilisation of citizens in order to reduce the harm often triggered by hate speakers in South Africa.

Keywords: social media, hate speech, cyberspace, internet

\section{Introduction}

First they came for the Socialists, and I did not speak out Because I was not a Socialist.

Then they came for the Trade Unionists, and I did not speak out - 
Because I was not a Trade Unionist.

Then they came for the Jews, and I did not speak out Because I was not a Jew.

Then they came for me - and there was no one left to speak for me ${ }^{1}$.

In the $18^{\text {th }}$ century, it was often said the 'pen is mightier than the sword' (Kelly 2003:23). In contemporary times, however, it could be said that keypads of mobile phones or computers are mightier than rifles or AK-47s. The evolution of cyberspace has demonstrated some positive outcomes such as easy access to information and for businesses purposes (Lange 2007). While the Internet has these impressive features, its evolution has also witnessed an increase in certain antisocial behaviours such as hacking, hoaxes and hate speech (Rosen 2012). The proliferation of these behaviours does not only erode the quality of life of their victims, but weakens social bonds (Demirbas 2017: 2693). To this end, human rights activists have cautioned that this development will expose disempowered groups such as women, blacks and gays to contempt and ridicule (Waldron 2012; Kimmel \& Kestenbaum 2015).

This paper uses the phrases 'hate speech', 'assaultive statement' and 'inflammatory speech' interchangeably to refer to all forms of prejudicial or biased communications -symbolic, written or verbal- that degrade or insult an ethnic or racial group. This definition encompasses a political speech calling for particular new policy or a strong misrepresentation of a specific group. It is, important to indicate that hate speech is not completely new in postapartheid South Africa, and even before the emergence of the Internet in the mid-1990s (Liebenberg 2000). Nevertheless, in the days before the Internet, dissemination of racial slurs, or defamation of a target required an individual to have access to a newspaper, radio or television, all of which cost money to attain (Matsuda 1989). Nevertheless, with the relatively cost-free and much easier nature of the Internet, these behaviours have become widespread (Tepker 2017). A key feature of the Internet which distinguishes it from the

${ }^{1}$ Martin Niemoller. Although the exact wording and source of this quote is subject to several variations, the quote is often attributed to Niemoller. While serving as a Protestant minister, he was an early supporter of Hitler, later imprisoned for eight years after leading his church's opposition towards the Nazis. 


\section{Bright Nkrumah}

pre-1990s medium of communication is that much of the materials posted are not easily erasable (Dauterman 2003). For that reason, when an inflammatory statement 'goes viral', it might attract a lot of attention from different viewers and perhaps remain accessible for posterity to witness (Demirbas 2017: 2693). In this vein, the primary question the next section seeks to answer is: why is there so much intolerance on the Internet in post-apartheid South Africa? In order to respond to this overarching question, the next section undertakes a brief assessment of the country's underlying values through a review of the structural conditions that enhance racial hatred and intolerance.

\section{Conceptual Framework What is Hate Speech?}

Inflammatory statement can potentially stimulate deadly stampede or violence. The very essence of inflammatory statement is usually to make victims objects of humiliation and contempt, thereby denying them their humanity (Chabalala 2017). It is important to indicate that hate speech has been, and can be, defined in various ways. For instance, in a broader sense, article 4 of the International Convention on the Elimination of all Forms of Racial Discrimination defines hate speech as 'dissemination of ideas based on racial superiority or hatred.' The International Covenant on Civil and Political Rights, in more specific terms under article 20(2) requires criminalisation of '[a]ny advocacy of national, racial, or religious hatred that constitutes incitement to discrimination, hostility or violence'.

Hate speech could, therefore, be simply defined as statements which are degrading, hateful and prosecutorial. It is also an instrument used to target a historically oppressed group (Kelly 2003). It can also be used to convey a message of religious, racial or other trait-based inferiority (Rosen 2012). Six golden threads seem to run through the various definitions of hate speech. To be exact, it is: (i) degrading; (ii) hateful; (iii) persecutory; (iv) targeted at a historically disadvantaged group; (v) of racial inferiority; and (vi) targets vulnerable groups (Matsuda 2018).

Hate speech can take various forms and shapes. First, are inflammatory political speeches akin to the 2015 xenophobic statement made by the Zulu King and Adolf Hitler's 'Mein Kampf' (Smith 1939; Heiden 1941; Ndou 2015). Both share the assertion that any race or group of people who are not liked by that society should be exterminated, deported, imprisoned or enslaved. 
Second, are scientific theories that suggest that certain gender or racial groups are genetically inferior and should be segregated (Bobo 1988; Entman 1990). Third, is the calling of names or direct personal insult.

Yet, with South Africa's 1996 Constitution calling for equality of all races, hardly anyone in democratic South Africa maintains that prejudicial statement is acceptable (Ntsabo 2018). In other words, the norm against hate speech in South Africa is now firmly entrenched. Of course, this does not imply that the sporadic occurrence of derogation of blacks, African migrants or gay bashing does not occur. When they do, they rather receive a degree of public condemnation (Mathabane 2002). The battle against hate speech in South Africa, in sum, could be said to have been relatively won.

With the exponential growth of cyberspace as a means of communication, so has the impact of these insensitive conducts also become pervasive (Stolley 2016). In 2016, an unemployed estate agent, Penny Sparrow, fumed on Facebook that black South Africans, whom she referred to as 'monkeys' were being a source of discomfort to others on public beaches (Wicks 2017). She was ordered to pay R150 000 to the Adelaide and Oliver Tambo Foundation after being found guilty (Evans 2016). The second case is very stagy. A Standard Bank economist, Chris Hart ranted on Twitter about black people's sense of entitlement and their hatred for white people (Subramany 2016). Although he apologised later, his apology did not resonate with his employers leading to his untimely resignation (Rahlaga 2016).

It is important to indicate that the South African government is not alone in this dilemma. While hate speech is criminalised in most European nations, the right of free speech is jealously guarded without due regard to their abuse in most African Constitutions. ${ }^{2}$ Having observed the brutality of the

2 See Art 21(1)(a) of Ghana's 1992 Constitution; art 61 of the 2013 Constitution Zimbabwe. For instance, sec 61(1)(a) of the 2013 Zimbabwean Constitution indicates that everyone has 'a. freedom to seek, receive and communicate ideas and other information; $b$. freedom of artistic expression and scientific research and creativity'. Art 33 of the 2010 Constitution of Kenya indicates that 'Every person has the right to freedom of expression, which includes -

(a) freedom to seek, receive or impart information or ideas;

(b) freedom of artistic creativity; and

(c) academic freedom and freedom of scientific research. 


\section{Bright Nkrumah}

Rwandan genocide triggered by inflammatory statement, South Africa and the African community need to pay closer attention to the inherent worth of every individual (Mathabane 2002). This inherent dignity clearly provides justification for restricting the 'right' of the chauvinistic speaker to rant prejudicial words (Wawrzynski \& Stanco-Wawrzynska 2016). Allowing inflammatory statement to flourish may not only harm the victim, but the speaker as well. For instance, if granted the legitimacy of a global audience, the speaker will probably be entrenched in his or her hateful conduct.

Like Hart, typing extremist remarks on the Internet with the intention of getting a response has become a norm or a means of recreation. Within the online community, these people are disparagingly termed as 'trolls' (Solove 2007: 5). In order to make other users assume that the remark has received broad support, some trolls create several accounts to enable them post inflammatory speeches under one user and subsequently use their other accounts to add a response of affirmation (Demirbas 2017: 2693). Real life trolls, akin to the ill-favoured creature that attempted to consume the three Billy Goats Gruff by blocking the bridge, undermine the utility of Internet by terrorizing other users (Asbjørnsen \& Moe 1962).

Some social scientists have argued that due to South Africa's checkered past, most citizens grapple with issues relating to racial or ethnic tensions (Moran 2005; Wawrzynski \& Stanco-Wawrzynska 2016). On one level, South Africans believe in a set of mantra which perceives discrimination and racism as offensive. They see discrimination of any form as immoral. According to this mantra, all are equal in the sight of God, and everyone is either a brother or a sister (Mathabane 2002). All men are equal and the national values are highly non-discriminatory and race blind (Bell 2008). South Africans, therefore, resolve to ensure the full realisation of Desmond Tutu's 'rainbow nation' and, thus, feel disappointed when they fail in this respect (Wawrzynski \& Stanco-Wawrzynska 2016).

On another level, since gender, sexual orientation and racial attitudes are acquired at the formative years of one's life, usually from playground friends and parents, people sometimes find it difficult to overcome their deepseated dark instincts (Schraub 2016). So, regardless of these public values, some often behave according to a lower code of conduct when they are in their comfort zone or unaware that there is no third-party monitoring them (Moran 2005). As a result, a typical South African at work might feel free to refuse a promotion or an interview to an otherwise black compatriot, if she is under the 
assumption that this act will not be detected by superiors (Beaman 2008). This same person with cronies at a private gathering or at a bar, might also feel freer to tell a joke at the expense of African migrants in the country, Muslims, gays and lesbians.

Nonetheless, in another circumstance, this person might act in a different way. For instance, on the Sunday after a national event (either the Human Rights Day, the Freedom Day or the Day of Reconciliation), and the pastor at the local church decides to reflect on the importance of such an occasion, this person may declare that s/he is colour blind and behave accordingly. Should s/he be standing or seated next to a coloured, Indian or black person, s/he is more likely to strike a conversation about the powerful sermon or the beautiful weather. S/he may even invite the other to a family event or go hiking (Schraub 2016). Many South Africans, in sum, behave as if they subscribe to two different sets of standards, one for private moments and another for public conduct. While the latter is carefully picked, bearing in mind the situation one finds him/herself in, the first is often intuitive.

Post-apartheid public consciousness is shaped in online editorials which all too often, are filled up with racist insults (Solove 2007). As a result, the lives of many South Africans have been impacted negatively by cyber bullying, hate speech and other anti-social behaviours (Schraub 2016). For instance, a YouTube video of 'the coffin assault' sparked outraged and was seen by many black Africans as invoking painful memories of the dehumanising treatment endured during the apartheid regime (Chabalala 2017). In this case, two white farmers posted a video where they were forcing a black man into a coffin and threatening to put a snake inside and set the coffin alight. The farmers were both sentenced to more than 10 years imprisonment. While the evolution of the Internet has created space for expression, the use of this medium to incite hatred could be considered as one of the major setbacks to the advancement of human rights in the $21^{\text {st }}$ century (Schraub 2016). Some of these crimes span from hacking, pranks and hoaxes, scams, financial and consumer fraud, threats to identity theft (Wawrzynski \& Stanco-Wawrzynska 2016). There are a number of platforms available on cyberspace for individuals wishing to make life unbearable for their targets. These include, but not limited to the following:

Blogs serve as a medium for analysing broad range of topics, ranging from the author's thoughts on a subject, the diaries or routine of the author or anything s/he (dis)approves of. In addition to these minor usages, blogs could 


\section{Bright Nkrumah}

be used to expose government corruption and state's effort to limit freedom of speech (Hlongwane 2010). Besides these positive attributes, the anonymous nature of blogs could make it an ideal platform for perpetrators to cast aspersions against their foes or a section of the population who may not appeal to the author.

Second, popular among smart phone users, WhatsApp was introduced primarily to exchange voice notes, videos, photos and text. While playing a vital role in information dissemination, this medium has become a platform where perpetrators post on their group pages' hateful speeches about target groups (Kimmel \& Kestenbaum 2015). The application, thus, allows users of smart phones (children as well adults) to view and store offensive contents distributed by authors against people they dislike in their mobile phones.

Third, as a relatively recent innovation, Twitter enables users to send and receive short messages or comments, termed 'tweets' (Gragg \& Sellers 2010). Most of the comments are trivial, usually encompassing slight details of a persons' activities, meals and day. Tweets, however, may also be used by trolls to defame a particular target group, especially individuals who are well known in the news (Lange 2007).

Fourth, by serving as a means of Internet-based social communication, Facebook enables subscribers to contact a list of friends with whom they can receive updates and exchange messages (Ellison, Steinfield \& Lampe 2007). While materials on Facebook are often not extraordinary, it could be used by individuals or groups to sabotage. This could be done through criticism or concerted hate speech against administrators, defame teachers, bully unpopular targets who arouse(s) their anger (Chabalala 2017). In addition, Facebook poses a problem of privacy, particularly for the young South African who may be ignorant of how a photograph or a candid disclosure could tarnish their reputation later in life.

Fifth, as a platform for international file sharing, mainly homemade videos, YouTube is used by perpetrators to advocate violence or attack groups or damage a political opponent, as demonstrated in 'the coffin assault' case (Lange 2007).

Sixth, apart from covering simple issues such as how to pass matric or cook a local Zulu food, websites may be used as propaganda machinery against foreigners, gays or albinos. According to Delgado and Stefancic (2004), the allegation against websites as being an instrument for spreading hate is not entirely true since visitors may choose not to visit such sites. While their observation may 
hold some merits, other people who may fall outside the bracket of the target group may begin to believe the idea posted (Chabalala 2017). This idea will eventually become socially saturated and be perceived to be true (Kimmel \& Kestenbaum 2015).

Finally, among the most frequently used cyberspace platforms are text messages and e-mails (Szostek 2011). While being helpful as an (un)official medium of communication, they have also been used for venting contempt and hatred against victims. Racist or perpetrators of xenophobic attempts often circulate messages on emails or text messages to mobilise support from disgruntled South Africans to attack foreigners (Gupta, Sharda \& Greve 2011). For instance, list servers allow hate groups to circulate messages with relative confidence that the victim will not be privy to (Chabalala 2017). Thus, without the sender's name often detached from individualised emails, the opponents may not be able to respond since the sender may have switched off his computer or sent the message from a public terminal (Malhotra, Michelson \& Valenzuela 2012).

\section{Balancing Act: Reconciling Hate Speech and Freedom of Expression}

In South Africa, inflammatory statement is protected from the state's interference under the 1996 Constitution. Section 16(1) of the Constitution expressly indicates that everyone has the right to freedom of expression, which includes artistic creativity, freedom to impart information and freedom of the press.

It must be noted that unlike other instruments such as the First Amendment of the United States, section 16(1) guarantees both freedom of expression and speech. Since the purposes of inflammatory statement is to promote intolerance and threatens the lives and liberty of those targeted, the drafters of the Constitution inserted a clawback clause to protect citizens from this form of abuse. The clause under section 16(2)(c) affirms that freedom of expression does not extend to 'advocacy of hatred that is based on race, ethnicity, gender or religion, and that constitutes incitement to cause harm'.

Inflammatory statements cannot only reinforce possibly harmful thoughts in the minds of the observers, but can also cause real psychological harm to the victims. Besides psychosomatic disease, the racist messages that prejudicial statements convey, have been shown to be linked to mental illnesses and have significant adverse impact on parenting practices (Nahay 1986). 


\section{Bright Nkrumah}

Many observers, therefore, called on the government for an urgent legal regulation to ensure behaviour change (Stolley 2016; Wicks 2017). Against this backdrop, the government at the beginning of 2017 announced plans for tabling legislation before parliament on hate speech, termed Prevention and Combating of Hate Crimes and Hate Speech Bill (DOJ\&CD 2018).

The promulgation of the bill was a response to highly-publicised matters or incidents of hateful statements which according to one observer 'shock the collective conscience of reasonable members of society' (Dube 2017). The bill, among others, seeks to criminalise hate speech triggered by prejudice (Dube 2018). The intention of the bill is a welcome development as it serves as a deterrent to would-be offenders. Given that citizens often have contempt towards legislations which do not resonate with their interest, this bill if passed, might enjoy a considerable public acceptance.

It must, however, be noted that the bill is not wholly relevant for two reasons. First, the Constitution sets out clear parameters on how the right to freedom of expression should be exercised (Van Staden 2018). In its widest possible sense, freedom of expression can be exercised except for serving as a platform for: a) advocating hatred based on religion, gender, ethnicity; (b) incitement of imminent violence; or (c) propaganda of war. The first threshold is unique in that it is the only expression in the Constitution which proscribes by using phrases such as 'incitement to cause harm' or 'advocacy'.

It is reasonable for a legislation to restrict certain kinds of freedoms, but such a limitation must be reasonable especially if that law is of general application. While the Constitution sets out only four grounds as constituting 'advocacy of hatred', section 3(1) of the hate speech bill lists an additional 13 grounds, comprising (a) sexual orientation; (b) sex including intersex; (c) political affiliation or conviction; (d) political affiliation or conviction; (e) occupation or trade; (f) nationality, migrant or refugee status; (g) language; (h) HIV status; (i) disability; (j) culture; (k) colour; (l) birth; (m) albinism; and (n) age. This overarching list broadly construes hate speech and, consequently, tramples on the freedom of the speech and freedom of expression. It reminds one the possible risk of 'insult bill' being adopted by the state to limit citizen's right to access information and censor the media (Dube 2018).

Before 1994, there were more than hundred pieces of laws all seeking to promote media censorship (Liebenberg 2000). With the collapse of apartheid, these legislations were repealed to usher in a constitutional 
democracy (Judge \& Nel 2008). It is, therefore, imperative that the freedom of the press is respected and protected, since the lifeblood of any democracy is an independent and investigative press (Barries 2013).

Second, an adoption of a hate speech bill will only be a duplication of the state's effort (Levy 2018). At present, there is an existing legal mechanism capable of addressing issues relating to hate speech. The Equality Court, created by the Promotion of Equality and Prevention of Unfair Discrimination Act 4 of 2000, is well positioned to adjudicate and order speakers to make a public apology or pay damages in light of the seriousness of the matter (Mitchley 2018). The relevance of the court is better demonstrated in the Sonke Gender Justice Network v Malema, where the respondent was ordered to pay $\mathrm{R} 50,000$ in damages to a non-governmental organisation on charges of hate speech (Sonke Gender Justice 2009).

Nonetheless, after more than two decades into democracy, South Africa still lacks a comprehensive hate speech legislation which could ensure the effective prosecution of perpetrators while deterring others. To be exact, by October 2018, South Africa has not yet passed into law the recently framed hate speech bill. It could be argued that government's inaction against perpetrators, as demonstrated in Hart's and Sparrow's cases, clearly indicates that speakers have the right to vent what they feel, irrespective of the impact of such statement. The targeted victim of abuse is entitled to state's protection, but, considering that the state cannot simultaneously protect both the perpetrator and victim, the government in most instances chooses to protect the speaker's right of expression (Van Staden 2018).

Yet, in February 2016, the state took an unprecedented turn when it handed down its first decision relating to the prosecution of this crime (Levy 2018). An estate agent Vicki Momberg made a video of her ranting about the incompetence of 'kaffirs' after being a victim of hijacking (Huffpost 2018) . $^{3}$ In 2017, the Randburg Magistrate Court found her guilty of four counts of crimen injuria and sentenced to two years in prison. ${ }^{4}$ Thus, rather than adopting an extra legislation, the government must reflect on ways of making the courts more appealing to the public, especially since it has the potential of consolidating the country's reconciliation project (Barries 2013). Further, to

\footnotetext{
${ }^{3}$ Kaffir is a derogative term for black Africans.

${ }^{4}$ Crimen injuria refers to the use of racially offensive language to wilfully cause an injury to a persons' dignity.
} 


\section{Bright Nkrumah}

ensure that the objectives of the hate speech bill do not flout other forms of freedoms, it is important that the provisions of the bill are narrowly defined to be aligned with the parameters of the Constitution (Levy 2018).

\section{The Conundrums of Regulating (Hate) Speech}

Government limitation of inflammatory statements seems to raise concerns among sections of the public (Judge \& Nel 2008). To some, the (over)regulation of any form of speech threatens to limit important right and undermine the basic tenets of democracy. Beyond being essential for personal autonomy, freedom of speech is key to advancing individual liberty (Feinberg 1988). Regulating this freedom may not only impact negatively on persons but may also endanger democracy (Levy 2018). Over-regulation of prejudicial statements can make hateful ideas more appealing to impressionable young South Africans, while leading to lionization of racist thugs, especially when the mask of taboo is placed on hate speech (Matsuda 1989). Moreover, total bans on hateful statement can harm potential victims given that it can underpin the paternalistic notion that the vulnerable are in need of state protection, thereby turning trolls into celebrated martyrs of libertarianism (Judge \& Nel 2008).

The potential regulation of assaultive statement in South Africa brings to bear ten main challenges. First, the dualistic nature of human dignity. Human dignity, from one context demands autonomy (Habermas 2010). The dignity of citizens may be considered as trampled upon by the state if that regime does not respect the public's beliefs and choices (Chaskalson 2000). It is imperative that a state allows its citizens to determine and shape their own identities and views, as set out in the Founding Provisions and Bill of Rights of the South African Constitution (Gross 1998). Arguably, the notions of liberty and dignity appear to be constantly at odds with each other. The concept, 'dignity as liberty' suggests that citizens have freedom of expression, whereas 'dignity-as-constraint' demands that hateful statement or unfettered contempt must not be permitted (Gross 1998). Although it may curtail the prejudicial statements of a hateful propagandist, (over)regulation of hateful speech may equally threaten human dignity.

Second, the interpretation and implementation of free speech and dignity varies at the national to the regional levels. Countries often have different approaches towards balancing these two contentious rights. For instance, sec $61(5)$ of the 2013 Constitution of Zimbabwe, only prohibits 
freedom of the media and expression only when they cause unwarranted or malicious violation of a person's right to privacy, incite violence, advocate hatred or hate speech, and cause malicious injuries to a person's dignity or reputation. Also, whereas the collection of Nazi memorabilia is prohibited in European countries, a speech may only be considered inflammatory in the American system when it threatens to trigger immediate violence (Levy 2018). With the wide coverage of the Internet, a racial supremacist can transmit hate propaganda from an American state where it is not a criminal offence, and stream into South Africa where it is illegal (Botha \& Govindjee 2014).

Third, granted that most states in the global south and north agree on a common basic system to protect freedom of expression and forestalling hate speech, it would still be difficult to achieve a global solution. This may be a daunting task mainly because historical and social context plays a key role in the process of determining which statements are inciteful and/or hurtful (Reddy 2002). Human dignity, as described by Klug (2003) is a manifestation of a sense of being which is imbedded and simultaneously personified in the engagement between the community and the individual. In similar vein, former president of the Constitutional Court, Justice Chaskalson (2000) points that human dignity embodies the right of each person not to be treated in a humiliating or devalued and respect for the autonomy of each person. The major hateful statements are those which seek to awaken dormant cultural prejudices by relying on historically established hatreds and symbolism (Tseis 2009). This provides the rationale why some scholars have intimated that considering the complexity of hate speech, there is the need for local or provincial governments to adopt different strategies and/or legislations which reflect the specific local history and practice (Patni \& Kaumudi 2009; Battaglia 1990; Smolla 1990). The relevance of local differences in triggering hateful statement becomes particularly challenging in the context of the Internet - a person in South Africa may post statement possibly offensive about sexual minorities that might be mildly derogatory in this country, although perilous in the context of the historical and social situations of an LGBTI viewer in Ghana (Bakircioglu 2008). It can be challenging to limit hateful statement when the individual making such a speech is unaware of the potential negative impact that their words may stimulate in different parts of the world (Patni \& Kaumudi 2009).

Fourth, South Africa's multi-racial and culturally diverse society presents further complications to regulating hate speech (Bakircioglu 2008). 


\section{Bright Nkrumah}

The definition of hate speech, as well as its impact can differ from provinceto-province and municipality-to-municipality in light of the various cultural differences. Different cultures may assign different interpretations to a word (Botha \& Govindjee 2014). For instance, while being thick skinned is considered offensive in some European quarters, according to Reichman (2007), this attribute is perceived as a positive trait in some (South) African societies. The psychological impact of hate speech and its possibility to trigger violence are both possibly heightened, especially in places where traditional conceptions of honour are of cultural significance (Cuyler 2011).

Fifth, according to Johnson and Post (1996), the lack of consensus at the regional and (inter)national levels regarding the definition, content and what constitutes a hate speech has aggravated issues surrounding jurisdictions. Social networks, in effect exists nowhere in particular, but rather everywhere. Website physically located in Pretoria has equal effect on people living in Durban, as it does on people physically located in Pretoria (Cuyler 2011). Thus, although they are located 'nowhere', websites impact on individuals everywhere. Given that the Internet is not confined to state borders, trolls can post hateful messages from locations which can sometimes be difficult for state's security agencies to trace (Levy 2018). While surfing the web, Internet users have real physical position which are traced by IP addresses, a system which tech-savvy persons can alter, making it seem like the user is surfing the website from another province and with a different machine. Therefore, assigning territory in terms of the location of machines could be unsatisfying, for two reasons: first, there is no necessary connection between an Internet address and a physical jurisdiction; and second, the system is unresponsive to the physical position of these machines. Although it could be argued that online content is physically located on the servers where the data is stored, it must be noted that it is only the location in a virtual space which comprises the machine's 'addresses' between which information and messages are routed. One approach which could be used by South Africa is to monitor activities online. This strategy, nonetheless, will compromise the privacy of citizens, especially whenever they open a profile on a social networking site, read a message board or visit a chat room.

Sixth, an important argument which has been advanced is that jurisdiction can be extended based on the physical location of the registry or the corporation in charge of handing out domain names and matching content with the Uniform Resource Locator (URL). One major reason counters this 
argument. First, countries with more popular companies (like the United States) will have a high amount of control over the cyberspace, leaving countries like South Africa with less domestic social networks little opportunity to address harms that might be triggered by the web within its territory.

Seventh, there are serious issues regarding the legitimacy of national regulation of the cyberspace, along with the logistical challenges in determining which state has jurisdiction. When a group of people enter into an agreement with a foreign company, or goes for a vacation in another country, they are made aware on notice that their conduct is subject to and/or must conform to the foreign law. Generally, such a notice is missing in cyberspace. Regulation of the cyberspace will subject users to different legislations of national states, subject Internet users to different overlapping and possibly even conflicting legislations. The legal challenges relating to the regulation of, and subjection of the Internet to a national legislation is better demonstrated in the 2010 Italian case where three Google executives were prosecuted for breaching the country's criminal legislation after some teenagers uploaded a video showing a disabled classmate being bullied (D'Alessandro 2010). The video, which was uploaded onto the Google owned website Google Video, climbed to the top of Google Italy's 'most entertaining' video list as it quickly attracted enormous attention. Even though the company took down the video within hours of it being called to its attention, an Italian court held that by making it accessible to viewers, the company had breached national privacy laws. As legal representatives of the company they work for, the employees were given six months suspended sentences. The judgement, in essence, placed a legal obligation on the company for not reviewing content prior to letting it be uploaded.

While the impact of the judgement at the global level may not be particularly problematic, within the national boundaries of Italy it could be ideologically challenging. It must be noted that from a human rights perspective, whereas the court's decision holds some merits, it will be difficult for the company to forestall future posting of such videos. Whereas it might be feasible to analyse a small fraction of videos posted by Italians, it is not practicable to assess the various videos accessible to all viewers in the country. Google's dilemma would be doubled if several other countries (as well as those in other regions- start to demand an enforcement of their domestic legislation) obliging the company to examine all videos in order to ensure compliance with, 


\section{Bright Nkrumah}

for example, Uganda, Zimbabwe, Ghana, South African legislation, would be a herculean task. The result of such a liability could inhibit technological advancement, limit the availability of Internet services and hinder innovation, given that such a liability would drastically affect the feasibility of Internet services and applications in South Africa and the world beyond.

Eighth, aside the recommendation that a country like South Africa should simply refrain from regulating cyberspace is the fact that it will be unrealistic for it to implement the regulation. The string of litigation in relation to the sale of Nazi memorabilia on the web services provider Yahoo! clearly illustrates this complexity. In one case, the website created a platform for auction where people could offer items and other users could bid on. French groups filed a petition against the website when some users listed Nazi memorabilia, given that the display of such items for sale was a breach of the countries criminal law (Bellia, Berman \& Post 2007). Despite the fact that the said materials were not listed on the Yahoo! Website in France (www.yahoo.fr), it was connected to the website in the United States (www.geocities.com), where one could purchase the memorabilia. The government of France asserted sovereignty by ordering the website to forestall any access to the auction service, since the damage was suffered within its territory. Although it attempted to comply with the order by amending the auction policy as well as posting warnings, Yahoo! did not take down the auction website nor block French users from accessing and viewing the prohibited items on the auction site. A US Federal Court, in a response to the French government's threat of imposing a FF1,00,000 fine, refused to enforce this decision by holding that such an order was in violation of the First Amendment to the US Constitution (Yahoo! Inc). As demonstrated by this case, a nation deciding that it has jurisdiction to enforce sovereignty online is not as simple. Before such a jurisdiction could have any merit, it is important that that state convinces other states of the relevance of such regulation, which could be burdensome in light of the needed resources to achieve this end.

Also, the lack of consensus among states over the proper balance between human dignity and free speech could also make the question of jurisdiction difficult to address at the national level. Simple statements concerning whether a conduct is appropriate could even be contested, presumably because different states may not share the same view on the meaning of what constitutes hate speech. Nonetheless, it can be particularly burdensome for South Africa to prosecute online behaviour effectively, 
including those which have severely impacted on its sovereign boundaries due to the borderless nature of the Internet.

Ninth, another problematic solution is that of international regulation and coordination. Due to the massive amounts of information that travel online, conventional procedures that control transnational activities are not easily transferable to the Internet. The adoption of and/or universal ratification of a particular international treaty to regulate cyberspace seems to be impracticable. For instance, the International Telecommunication Regulations (ITRs), signed by 89 out of a possible 144 countries will have little impact on South Africa's attempt to regulate the Internet and the regulation of hate speech (BusinessTech 2012). The prime objective of the regulation is to guarantee greater governmental oversight of cyberspace, including the Internet. Without universal ratification (particularly with the abstention of most countries including much of Europe and the US), hate speakers from any of these nonratifying countries could continue to disseminate assaultive pronouncements across the globe and into South Africa (ITU 2018).

Tenth, it would be challenging to frame a legislation to address Internet hate speech which is explicit enough to be meaningful but not conflicting with the domestic legislations of at least some of other nations'. First, in contrast to South Africa and the rest of sub-Saharan African countries who have signed the ITRs, the US has taken an anomalous position on the regulation of hate speech and protects it. Second, considering that most of the popular registries (or website companies), comprising the ones which administers all the websites with '.com' are positioned within its borders, the US, therefore, has a disproportionate control over the Internet, and yet not a party to the ITRs. Accordingly, any attempt to draft an international treaty with more moderate provisions towards striking a balance between freedom of speech and other fundamental rights is more likely to be frustrated by the USA's unwillingness to ratify a treaty which breaches its First Amendment.

In sum, although South Africa has demonstrated its willingness to address hate speech by drafting the hate speech bill, it remains to be seen whether the bill (if passed) could actually deter hate speakers, especially in view of the legal and technological conundrums set out above. Since it is not the objective of the paper to merely bring up problems without a solution, the paper now takes a look at some of the (un)conventional approaches which could be used by both citizens and the state to curb hate speeches in the country. 


\section{Deterrence: Shifting Regulation from State to Citizens}

Some of the conventional remedies used to address hate speech on cyberspace often encompasses those often used by victims against their aggressors, like talking back to their attacker. Most of these perceived remedies, as will be demonstrated below, often do not yield the expected result. For instance, talking back to the hate speaker is impracticable especially for a statement that is posted on a platform of the like-minded and is anonymous.

Proponents of freedom of expression equally recommend that anytime someone reads or hears something offensive, they must not quickly run to report to the state authorities, rather they must learn to harden themselves (Massaro 1991; Bakircioglu 2008). This suggestion is highly impracticable, especially in terms of speeches that suddenly pops up on your phone or computer screen, and one does not have the ample time to toughen up beforehand. Moreover, considering that one is usually not aware that such defamation is occurring or that one's good name or identity has been impugned, it could be difficult to put this approach into effect when it comes to prejudicial statement on the Internet. Besides failing to entreat attackers to refrain from their antisocial behavior, this strategy places the onus of battling prejudicial statement on innocent and vulnerable South Africans who are victims of such acts (Massaro 1991).

An additional riposte from proponents of free speech is that victims must learn to endure without responding to hate speakers. According to Johnson and Post (1996), such speeches act as a pressure valve which allows aggressors air their feelings in a harmless manner, and that if bottled up, may later burst out in even more destructive way (Khaliq 1994; Dauterman 2003). This notion is misleading, especially within the context of the Internet. Far from pacifying the attacker and his/her followers, the first rant attracts likeminded attackers, and a response of 'likes' or 'right ons' boosts the morale of the hate speaker that his statement is true and shared widely, when in actual fact that is not the case (Castagna 2013).

Despite the few cases adjudicated by the courts in South Africa, the judiciary has given relatively little attention to hate speeches. Considering that the judiciary consider Internet speeches as falling under section 16 of the 1996 Constitution, it is more likely that the Constitutional Court will not favor any law in the form of hate speech which seeks to limit citizens right to speech on the Internet. Such a law can only pass a constitutional muster if it only seeks to forbid speeches resembling incitement to cause harm, hatred based on 
ethnicity, incitement of imminent violence and propaganda for war. Given that prejudicial statements are likely to spread among loners operating in secrecy or like-minded groups, new strategies must be sought (Cuyler 2011). The next section analysis and recommends three key strategies to forestall the upsurge of hate speeches, namely, sanctions, boycotting and group contact.

The first, and often more effective weapon of gaining the attention of hate speakers is through economic sanction or protest. Some of these agitators sometimes own a business or are employees of an entity which may need either a monetary assistance from the government, an advertising account, a tax deduction, donations or funds for operations. Sanctions in the form of a letter to the South African Revenue Service calling the aggressor's business into question, withdrawal of business license and most importantly consumer boycott may gain their attention. For instance, on 13 January 2018, members of the Economic Freedom Fighters vandalized H\&M stores in Sandton City and Menlyn (Makhob 2018). The boycotting was triggered by the clothing retail giant's latest advert portraying a black boy wearing a sweater with the inscription 'coolest monkey in the jungle'. According to the protesters, this inscription contravenes the country's transformation efforts (Castagna 2013). This type of sanctions will nudge attackers to behave in a less socially spiteful manner and to moderate their antisocial activity, since most groups and individuals guard zealously their own financial fortunes.

Morever, as its name implies, the approach of social contact seeks to prevent prejudicial statements by creating platforms for different sections of the population to come together and interact with one another, usually in group settings. The best approach of reducing discriminatory prejudices through social contact is by assigning similar tasks to members of different races and ethnicities (Nahay 1986). The pursuit of similar goals and objectives will help the members interact and make the prejudiced person more comfortable in mixed-race setting. Such avenues may include sports, schools and series of recreational activities. This notion asserts that much of gender, racial and sexual orientation friction and discrimination are triggered by wrong perception (Nahay 1986). From the infancy, a person internalizes an idea, mostly from playmates or parents that a section of the country's population or individuals from a particular race are not trustworthy. In order to counter this perception, the state must create several platforms for South Africa's youth to engage with other races and where necessary, with different sexual orientation. Through constant interaction, they will figure out that some of the things they 


\section{Bright Nkrumah}

were told were not completely true (Demirbas 2017). Ultimately, they will discover that those with dark-skinned, and/or with different sexual orientation are not much different from them, with some being honest others deceitful, some nice others arrogant, some smart others dump. As witnessed in some parts of the country, some might end up being friends with members of other races. People who are raised in an environment with people of different backgrounds are more comfortable living or working with individuals of different racial group, choose companions of different backgrounds, and in the long run are more comfortable with diversity.

\section{Conclusion}

Whereas the Internet has brought individuals from all over the world together through a simple means of communication, it has, however, created a barrier since it allows individuals to hurt others in ways that were not possible in the past. The potentially massive audience that one can attract, coupled with the anonymity of the Internet has triggered growing and serious problem in the form of hateful speech.

South Africa's specific trajectory of exclusion and marginalisation needs to be examined within the constitutional lens of transparency, accountability and openness. Ultimately, this requires that the country strikes a balance between non-discrimination, freedom of expression as well as hate speech. Although the present hate speech bill deviates from this balancing act, it can be salvaged by narrowly defining hate speech and giving more visibility to the equality court. Besides national regulation, it would be extremely cumbersome for the international community to agree on a single treaty which addresses hate speech on the Internet, especially in light of the different perspective of nations regarding what constitutes hateful pronouncements.

Regulating hate speech can be challenging with serious repercussions involving human rights issues on both sides of the argument. Moreover, it appears that government policing or regulation of the Internet is unlikely to produce a solution to the problem. This may be due to issues of illegitimacy and the challenge of translating national jurisdiction into cyberspace as well as the disagreement over the importance of free expression. This challenge ultimately leaves the solution towards addressing hate speech largely in the hands of citizens, in the form of popular action. Given that hate speakers may be involved in an economic activity, mobilisation of citizens against such an 
individual or an organisation, mainly through sanctions and boycotting any economic venture could moderate these extremes.

\section{Bibliography}

Asbjørnsen, P.C. \& J. Moe 1962. Norske Folkeeventyr. Norway: Anden forøgede Udgave.

Bakircioglu, O. 2008. Freedom of Expression and Hate Speech. Tulsa Journal of Comparative \& International Law 16,1: 1 - 50.

Barries, G.N. 2013. The Divergent Constitutional Approach to Hate Speech in South Africa and the United States. Journal of South African Law 697 707.

Battaglia, J.M. 1990. Regulation of Hate Speech by Educational Institutions:

A Proposed Policy. Santa Clara Law Review 345 - 392.

Beaman, L. 2008. Defining Harm: Religious Freedom and the Limits of the Law. Canada: UBC Press.

Bell, D. 2008. Racism as the Ultimate Deception. North Carolina Law Review 86, 3: $621-634$.

Bellia, P.L., P.S. Berman \& D.G. Post 2010. Cyberlaw: Problems of Policy and Jurisprudence in the Information Age. London: Thomson/ West.

Botha, J. \& A. Govindjee 2014. Regulating Cases of Extreme Hate Speech in

South Africa: A Suggested Framework for a Legislated Criminal

Sanction. South African Journal of Criminal Justice 27, 2: 117 - 155.

BusinessTech. 2012. Global Telecom Treaty Signed by 89 Nations. Available

at: https://businesstech.co.za/news/telecommunications/28782/global-

telecom-treaty-signed-by-89-nations/ (Accessed on 23 November 2018.)

Chabalala, J. 2017. Coffin Assault Duo will Approach SCA to Challenge Sentences. News24. Available at:

https://www.news24.com/SouthAfrica/News/coffin-assault-duo-willapproach-sca-to-challenge-sentences-20171109.

(Accessed on 14 March 2018.)

Chaskalson, C.J.A. 2000. Human Dignity as a Foundational Value of our Constitutional Order. SAJHR 193 - 205.

Cuyler, A. 2011. Social Networking: Leveraging Twitter, LinkedIn, and

Facebook. Connecticut Lawyer 22,3: 27.

DailyMail 2017. Shocking Video of 'Coffin Assault' in South Africa Shown 
in Court. MailOnline. Available at:

http://www.dailymail.co.uk/video/news/video-1513281/Shocking-videocoffin-assault-South-Africa-shown-court.html

(Accessed on 25 November 2018.)

D’Alessandro, M. 2010. Google Executives Convicted for Italy Autism Video.

Reuters. Available at: https://www.reuters.com/article/us-italy-googleconviction/google- executives-convicted-for-italy-autism-videoidUSTRE61N2G520100224. (Accessed on 21 November 2018.)

Dauterman, W.C. 2003. Internet Regulation: Foreign Actors and Local Harms - At the Crossroads of Pornography, Hate Speech, and Freedom of Expression. North Carolina Journal of International Law and Commercial Regulation 28,1: 179.

Delgado, R. \& J. Stefancic 2004. Understanding Words that Wound. US: Westview Press.

Demirbas, T. 2017. Hate Speech and Hate Crimes. Dokuz Eylul Universitesi Hukuk Fakultesi Dergisi 2,4: 2693 - 2702.

DOJ\&CD (Department of Justice and Constitutional Development) 2018. Prevention and Combating of Hate Crimes and Hate Speech Bill. Available at:

http://www.justice.gov.za/legislation/bills/2018-HateCrimesHateSpeechBill.pdf (Accessed on 14 March 2018.)

Dube P. 2018. On the Revised Hate Speech Bill 2018. In Politicsweb. Available at:

https://www.politicsweb.co.za/opinion/the-new-and-improved-2018hate-speech-bill (Accessed on 28 November 2018.)

Dube, P. 2017. Rescuing the 'hate speech bill'. In News24. Available at < https://www.news24.com/Columnists/GuestColumn/rescuing-the-hatespeech-bill-20170307. (Accessed on 23 November 2018.)

Ellison, N.B., C. Steinfield \& C. Lampe 2007. The Benefits of Facebook 'friends'. Social Capital and College Students' Use of Online Social Networks Sites. Journal of Computer-Mediated Communication 12, 4: 1143-1168.

https://doi.org/10.1111/j.1083-6101.2007.00367.x

Evans, J. 2016. Penny Sparrow Back in Court on Criminal Charges for Racist Comments. City Press. Available at:

https://city-press.news24.com/News/penny-sparrow-back-in-court-oncriminal-charges-for-racist-comments-20160912 
(Accessed on 27 November 2018.)

Feinberg, F. 1988. Offense to Others. London: Oxford University Press.

Government Gazette No. 41543 of 29 March 2018.

Gragg, P. \& C.L. Sellers. 2010. Twitter. Law Library Journal 102, 3: 325 330.

Gross, A. 1998. Property as a Constitutional Right and Basic Law: Human Dignity and Liberty. Tel Aviv University Law Review 21,3: 419.

Gupta, A., R. Sharda \& R.A. Greve 2011. 'You've got email': Does it Really Matter to Process Emails Now or Later? Information Systems Frontiers 13,5: $637-653$.

https://doi.org/10.1007/s10796-010-9242-4

Heiden, K. 1941. Hitler's Better Half. Foreign Affairs 20,1: 73-86. https://doi.org/10.2307/20029131

Hlongwane, S. 2010. SpeakZA: Bloggers Speak Out on Free Speech. Available at:

http://thoughtleader.co.za/siphohlongwane/2010/03/24/speakzabloggers-speak-out-on-free-speech/ (Accessed on 25 November 2018.)

Huffpost 2018. Vicki Momberg to be Sentenced for Racist Rant. Available at https://www.huffingtonpost.co.za/2018/03/09/vicki-momberg-to-besentenced-for-racist-rant a 23381244/

(Accessed on 29 November 2018.)

International Telecommunication Union (ITU) 2018. International Telecommunication Regulations (ITRs). Available at:

https://www.itu.int/en/wcit-12/Pages/itrs.aspx.

(Accessed on 28 November 2018.)

Johnson, D.R. \& D. Post 1996. Law and Borders - The Rise of Law in Cyberspace. Stanford Law Review 48,5: 1367 - 1402. https://doi.org/10.2307/1229390

Kelly, C.A. 2003. The Pen is Mightier than the Sword or Why the Media Should Exercise Self-Restraint in Time of War. Florida Bar Journal 77,1: $22-29$.

Khaliq, N. 1994. Striking a Balance: Hate Speech, Freedom of Expression and Non-Discrimination. Tolley's Journal of Media Law and Practice 15,1: $27-28$.

Kimmel, L. \& J. Kestenbaum. 2015. What's up with WhatsApp: A Transatlantic View on Privacy and Merger Enforcement in Digital Markets. Antitrust 29,1: 48 - 55. 
Knepper, P. 1996. Race, Racism and Crime Statistics. Southern University Law Review 24,1: 71 - 112.

Lange, P.G. 2007. Public - Private and Privately Public: Social Networking on

Youtube. Journal of Computer-Mediated Communication 13, 1: 361 380.

https://doi.org/10.1111/j.1083-6101.2007.00400.x

Levy, M. 2018. MPs Question Whether Hate Speech Bill is Needed. DailyMaverick. Available at:

https://www.dailymaverick.co.za/article/2018-06-07-mps-questionwhether-hate-speech-bill-is-needed/. (Accessed on 23 November 2018.) Liebenberg, S. 2000. Human Development and Human Rights: South African Country Study. In Human Development Report 2000: Background Paper. Available at:

http://hdr.undp.org/sites/default/files/sandra_liebenberg.pdf. (Accessed on 23 November 2018.)

Makhob, N. 2018. EFF Shreds H\&M stores. City Press Available at:

https://www.news24.com/SouthAfrica/News/eff-shreds-hm-stores-

20180114-2. (Accessed on 29 November 2018.)

Malhotra, N., M.R. Michelson \& A.A. Valenzuela 2012. Emails from Official

Sources can Increase Turnout. Quarterly Journal of Political Science 7, 3: $321-332$.

https://doi.org/10.1561/100.00011073

Massaro, T.M. 1991. Equality and Freedom of Expression: The Hate Speech

Dilemma. William and Mary Law Review 32,2: 216.

Mathabane, M. 2002. Kaffir Boy: The True Story of a Black Youth's Coming of Age in Apartheid South Africa. Michigan: Gale.

Matsuda, M.J. 1989. Public Response to Racist Speech: Considering the Victim's Story. Michigan Law Review 87,8: 2320 - 2381.

https://doi.org/10.2307/1289306

Matsuda, M.J. 2018. Words that Wound: Critical Race Theory, Assaultive Speech, and the First Amendment. United Kingdom: Routledge https://doi.org/10.4324/9780429502941

Mitchley A. 2018. The Vickey Momberg Case: Equality Court vs Criminal Court. News24. Available at:

https://www.news24.com/SouthAfrica/News/the-vicki-momberg-caseequality-court-vs-criminal-court-20180404 (Accessed on 28 November 2018.) 
Moran, R.F. 2005. Whatever Happened to Racism. St. John's Law Review 79,4: 899 - 928.

Nagan, W.P. 1990. South Africa in Transition: Human Rights, Ethnicity and Law in the 1990s. Villanova Law Review 35,6: 1139 - 1174.

Nahay, J.B. 1986. Modern Racism, Ambivalence, and the Modern Racism Scale. In Dovidio, J. \& S. Gaertner (eds.): Prejudice, Discrimination, and Racism: Theory and Research. New York: Academic Press.

Ndou, C. 2015. 'Foreigners must go home' - King Zwelithini. The Citizen Available at: https://citizen.co.za/news/south-africa/349347/foreignersmust-go-home-king-zwelithini/. (Accessed on 28 November 2018.)

Neisser, E. 1994. Hate Speech in the New South Africa: Constitutional Considerations for a Land Recovering from Decades of Racial Repression and Violence. Journal of International Law and Practice 3,2: 336 - 356. https://doi.org/10.1080/02587203.1994.11827544

Ntsabo, M. 2018. Desmond Tutu says that Sexuality is not a Choice. Available at: http://www.mambaonline.com/2018/06/05/desmond-tutu-says-thatsexuality-is-not-a-choice/ (Accessed on 27 November 2018.)

Patni, R. \& K. Kaumudi 2009. Regulation of Hate Speech. NUJS Law Review 2,4: 749 - 778.

Patni, R \& K. Kaumudi 2009. Regulation of Hate Speech. NUJS Law Review 2,4: 749 - 778.

Rahlaga, M. 2016. Standard Bank's Chris Hart Confirms Resignation in a Series of Tweets. EyeWitness News. Available at:

http://ewn.co.za/2016/03/15/Standard-Banks-Chris- Hart-confirmsresignation-in-a-series-of-Tweets. (Accessed on 13 March 2018.)

Reichman, A. 2007. The Passionate Expression of Hate: Constitutional Protections, Emotional Harm and Comparative Law. Fordham International Law Journal 31, 1: 76 - 137.

Rosen, J. 2012. Who Decides - Civility v. Hate Speech on the Internet. Insights on Law and Society 13,2: 32 - 37.

Schraub, D. 2016. Racism as Subjectification. Berkeley Journal of AfricanAmerican Law \& Policy 17, 1: 3 - 46.

Sekhotho, K. 2018. Protesting EFF Members Disperse from Mall of Africa H\&M. EyeWitness News. Available at:

http://ewn.co.za/2018/01/15/protesting-economic-freedom-fighters-effmembers-disperse-from-mall-of-africa-h-and-m (Accessed on 27 November 2018.) 
Smith, S. 1939. The Kampf about Mein Kampf. Boston University Law Review 19,4: 633 - 644.

Smolla, R.A. 1990. Introduction: Exercises in the Regulation of Hate Speech. William and Mary Law Review 32,2: 207 - 210.

Solove, D.J. 2007. The Future of Reputation: Gossip, Rumor, and Privacy on the Internet. Connecticut: Yale University Press.

Sonke Gender Justice Network v Malema (2010 (7) BCLR 729 (EqC)) 2010. ZAEQC 2; 02/2009 (15 March 2010).

Sonke Gender Justice 2009. No-one is Above the Law: Equality Court Action against Julius Malema. Available at:

https://genderjustice.org.za/news-item/no-one-is-above-the-law-equalitycourt-action-against-julius-malema/ (Accessed on 23 November 2018.)

Stolley, G. 2016. Penny Sparrow Fined R 5000 for Racist Rant. In IOL. Available at: $\quad$ https://www.iol.co.za/news/penny-sparrow-fined-r5000-for-racist-rant-2067166 (Accessed on 29 November 2018.)

Subramany, D. 2016. Wits Responds to Queries about Chris Hart's Qualifications. In Mail\&Guardian. Available at:

https://mg.co.za/article/2016-01-06-questions-about-chris-hartsqualifications-answered-by-wits. (Accessed on 29 November 2018).

Szostek, A.M. 2011. 'Dealing with my emails': Latent User Needs in Email Management. Computers in Human Behaviour 27, 2: 723 - 729.

https://doi.org/10.1016/j.chb.2010.09.019

Tepker, R. 2017. 'Hate Speech'. Oklahoma Bar Journal 88,14: 947.

Tseis, A. 2009. Dignity and Speech: The Regulation of Hate Speech in a Democracy. Wake Forest Law Review 44, 2: 497 - 534.

Van Staden, M. 2018. Hate-speech Bill: A Threat to Democracy in South Africa. Huffpost. Available at:

https://www.huffingtonpost.co.za/martin-van-staden/hate-speech-bill-athreat-to-democracy-in-south-africa_a_23374035/

(Accessed on 28 November 2018.)

Waldron, J. 2012. The Harm in Hate Speech. Cambridge: Harvard University Press.

https://doi.org/10.4159/harvard.9780674065086

Wawrzynski, P. \&A Stanco-Wawrzynska. 2016. South African Post-Apartheid Transitional Remembrance Policy (1994-1999). Polish Political Science Yearbook 45: 145-156.

https://doi.org/10.15804/ppsy2016011 
Wicks, J. 2017. Penny Sparrow will Probably Die in Hiding, Says Daughter. TimesLive. Available at:

https://www.dispatchlive.co.za/news/2017-08-07-penny-sparrow-willprobably-die-in-hiding-says-daughter/ (Accessed on 29 November 2018).

Yahoo! Inc., A Delaware Corporation, Plaintiff-appellee, v. La Ligue Contre Le Racisme et L'antisemitisme, a French Association; L'union Des Etudiants Juifs De France, a French Association. Defendants-appellants, 433 F.3d 1199 (9th Cir. 2006).

Bright Nkrumah School of Social Sciences Howard College University of KwaZulu-Natal Bright.nkrumah@ukzn.ac.za 